\title{
Advanced Seismic Probabilistic Risk Assessment Demonstration Project Plan
}

\author{
Justin Coleman
}

September 2014

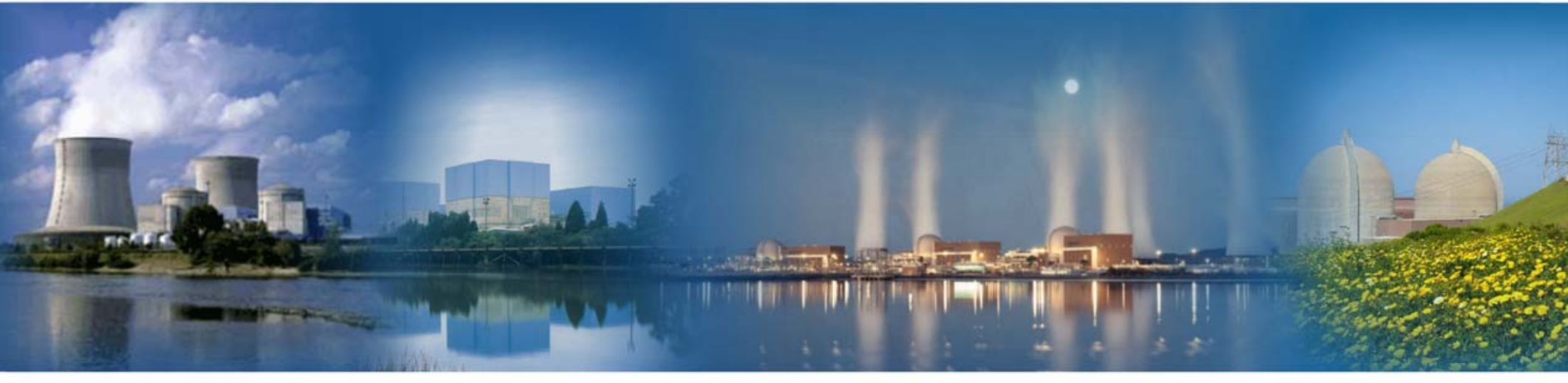

U.S. Department of Energy

Office of Nuclear Energy 


\section{DISCLAIMER}

This information was prepared as an account of work sponsored by an agency of the U.S. Government. Neither the U.S. Government nor any agency thereof, nor any of their employees, makes any warranty, expressed or implied, or assumes any legal liability or responsibility for the accuracy, completeness, or usefulness, of any information, apparatus, product, or process disclosed, or represents that its use would not infringe privately owned rights. References herein to any specific commercial product, process, or service by trade name, trade mark, manufacturer, or otherwise, does not necessarily constitute or imply its endorsement, recommendation, or favoring by the U.S. Government or any agency thereof. The views and opinions of authors expressed herein do not necessarily state or reflect those of the U.S. Government or any agency thereof. 


\title{
Advanced Seismic Probabilistic Risk Assessment Demonstration Project Plan
}

\author{
Justin Coleman
}

September 2014

Idaho National Laboratory Originating Organization NS\&T

Idaho Falls, Idaho 83415

http://www.inl.gov

Prepared for the

U.S. Department of Energy

Office of Nuclear Energy

Under DOE Idaho Operations Office

Contract DE-AC07-05ID14517 


\section{CONTENTS}

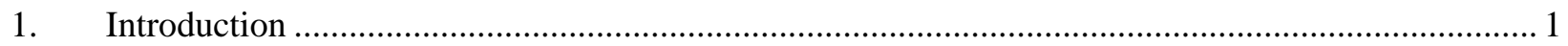

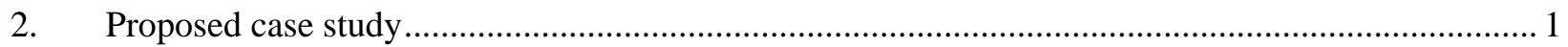

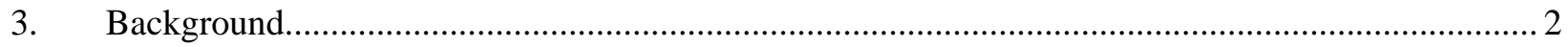

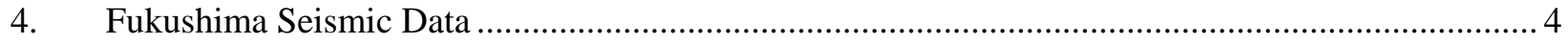

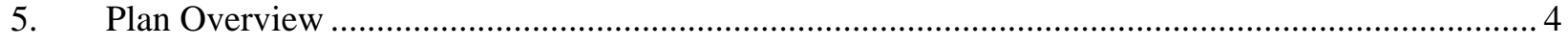

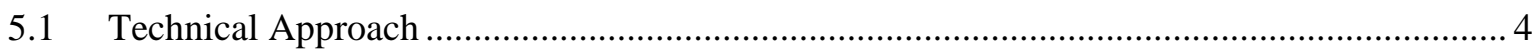

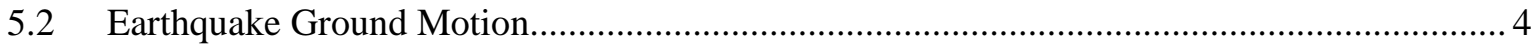

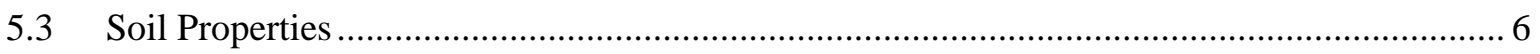

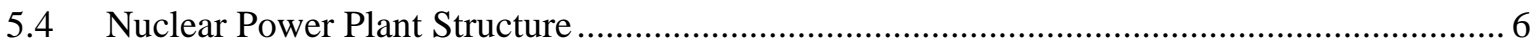

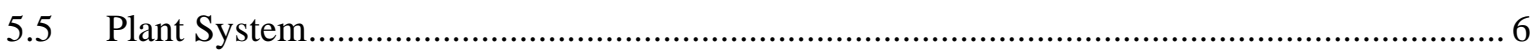

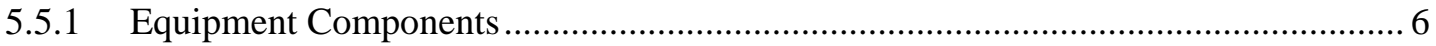

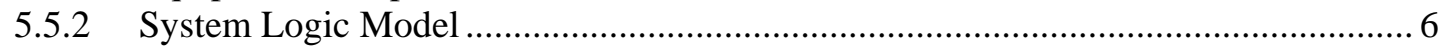

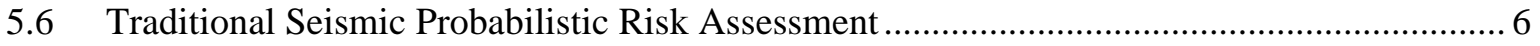

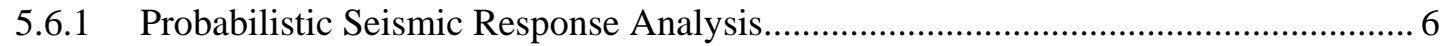

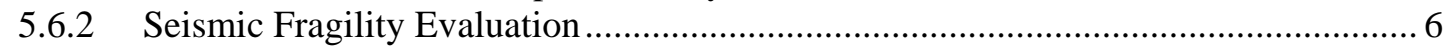

5.7 Advanced Seismic Probabilistic Risk Assessment by Nonlinear Soil-Structure

Interaction Analysis ..................................................................................................... 7

5.7.1 Nonlinear Soil-Structure Interaction Analysis ......................................................... 7

5.7.2 Component Response Distributions ................................................................... 7

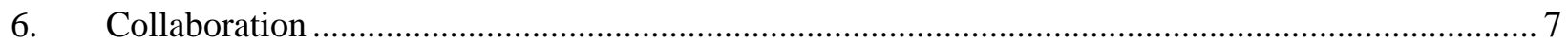

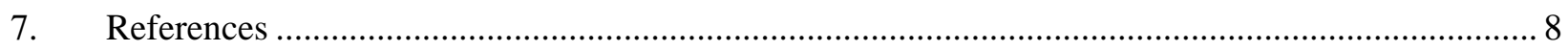

Appendix A: Fukushima Daichii site specific report ........................................................................ 9 


\section{Advanced Seismic Probabilistic Risk Assessment Demonstration Project Plan}

\section{Introduction}

Idaho National Laboratories (INL) has an ongoing research and development (R\&D) project to remove excess conservatism from seismic probabilistic risk assessments (SPRA) calculations. These risk calculations should focus on providing best estimate results, and associated insights, for evaluation and decision-making. This report presents a plan for improving our current traditional SPRA process using a seismic event recorded at a nuclear power plant site, with known outcomes, to improve the decision making process.

SPRAs are intended to provide best estimates of the various combinations of structural and equipment failures that can lead to a seismic induced core damage event. However, in general this approach has been conservative, and potentially masks other important events (for instance, it was not the seismic motions that caused the Fukushima core melt events, but the tsunami ingress into the facility).

The plan for development of advanced tools, methods for application in SPRAs is documented in Coleman (2014). In addition to developing tools and methodologies, it is important to use external hazard events that have already occurred at nuclear power plants (NPP) as case studies. Some recent seismic events that exceeded the design basis earthquake (DBE), also known as beyond design basis earthquake (BDBE), are:

- Seismic event recorded at North Anna (August 2011, detailed information provided in [Virginia Electric and Power Company Memo])

- Seismic and Tsunami events recorded at Fukushima Daiichi and Daini (March 2011 [TEPCO 1]),

- Seismic event recorded at Kaswazaki-Kariwa (2007, [TEPCO 2]).

These recent earthquake events offer a unique opportunity to improve the state of practice for calculating seismic risk at NPPs. Some opportunities are:

- $\quad$ Recorded earthquake response data, both free-field and in-structure, allows for development of more robust experience based seismic fragilities for some (SSCs). EPRI gathered this data at Fukushima Daini post event and is in the process of updated some SSC fragility curves. This data could also be used to evaluate seismic margins that exist in current nuclear power plant design basis.

- Advanced modeling and simulation tools are currently being developed at INL to perform nonlinear soil structure-interaction analysis (NLSSI). Seismic data gathered during these earthquakes could be used to validate these advanced tools.

- Use the recorded event in a case study to improve the current United States (US) SPRA methodology. The focus of this report is laying out a project plan for performing this case study.

\section{Proposed case study}

A case study using one of these seismic events presents the opportunity to improve our process for generating risk results. For instance let us consider the event at Fukushima Daichii for discussion. If we could go back in time (pre-event) and perform a traditional United States (US) based SPRA (again following the process) what decisions would you have made at that plant? Would the decision have been to seismically harden the diesel generators or other portions of that plant? Next postulate the Great Tohoku scenario (earthquake and Tsunami). See if the decisions based on traditional SPRA approach would have changed the outcome. If a decision was to harden the diesel generators then the wrong decision would have been made and the disaster would have still occurred. Was the decision to harden the diesel generators based on conservative seismic fragilities and building response models? If so we 
have an opportunity to learn from this event in the US and improve our seismic and flooding PRA methodology.

In this way the data and outcome of the Great Tohoku earthquake could be used to improve our seismic and flooding risk based decision process.

All of these items feed into a process known as risk-informed decision making, which is the key issue. We wish to answer questions such as how vulnerable are our nuclear power plants to a variety of internal and external events (including seismic), which makes the information gathered during BDBE's at Japanese and US NPP sites important.

The proposal is to perform the following tasks with the goal of trying to improve upon the tradiational SPRA approachs.

- Gather data including, seismic hazard data, seismic motions, tsnuami data, design basis values, plant dimensions, system and component information.

- Develop a working relationship with the Japanese

- Develop and perform Traditional seismic and flooding PRA's. Also develop inprovements to high fidelity tools to improve coupled seismic and flood modeling capabilities

- Perform advanced seismic and flooding PRA using high fidelity tools and continue to add additional features to the numerical tools

- Compare the two analyses and determine how to strength the advanced PRA approach

- Use this comparision to refine the advance SPRA methodology

\section{Background}

The background on the Fukushima disaster and data (recorded seismic data and soil site data) was gathered this year and is presented in more detail below.

Fukushima Daiichi NPP is owned and operated by the Tokyo Electric Power Company (TEPCO). The facility is located on the Japanese coastline, surrounded by the cities of Fukushima, Iwaki, Minamisoma, Nihonmatsu, and Sendai. Figures 1 and 2 depict the location of Fukushima Daiichi relative to the country boarders.
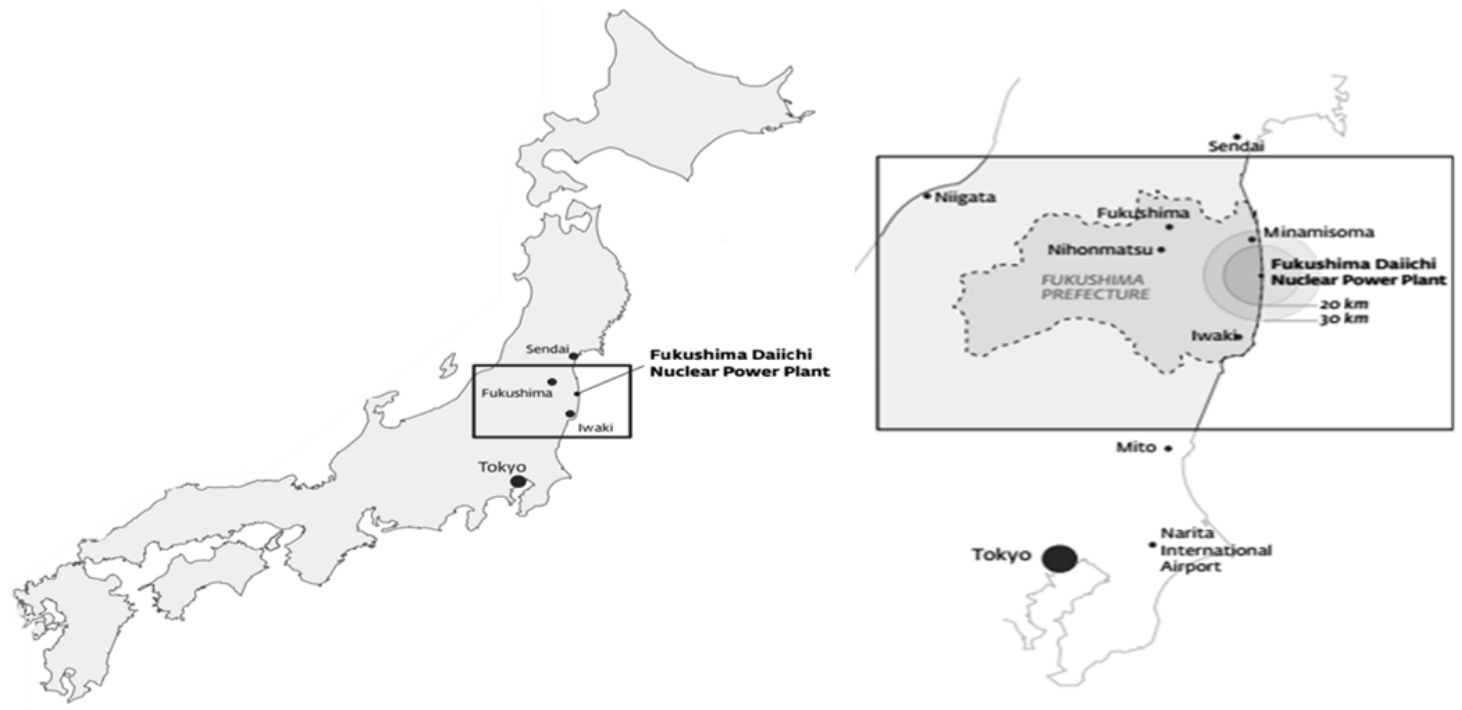

Figure 1: The country of Japan outlining cities relevant to the Fukushima Daiichi NPP
Figure 2: Magnifies the location of the Fukushima Daiichi NPP and surrounding areas 
The nuclear facility consists of Reactor Units 1 through 6. Details of the effects of the seismic and tsunami events on the reactors can be referenced in the NAIIC report. Figure 3, provided by the NAIIC report, outlines in detail the layout of the Fukushima Daiichi NPP.
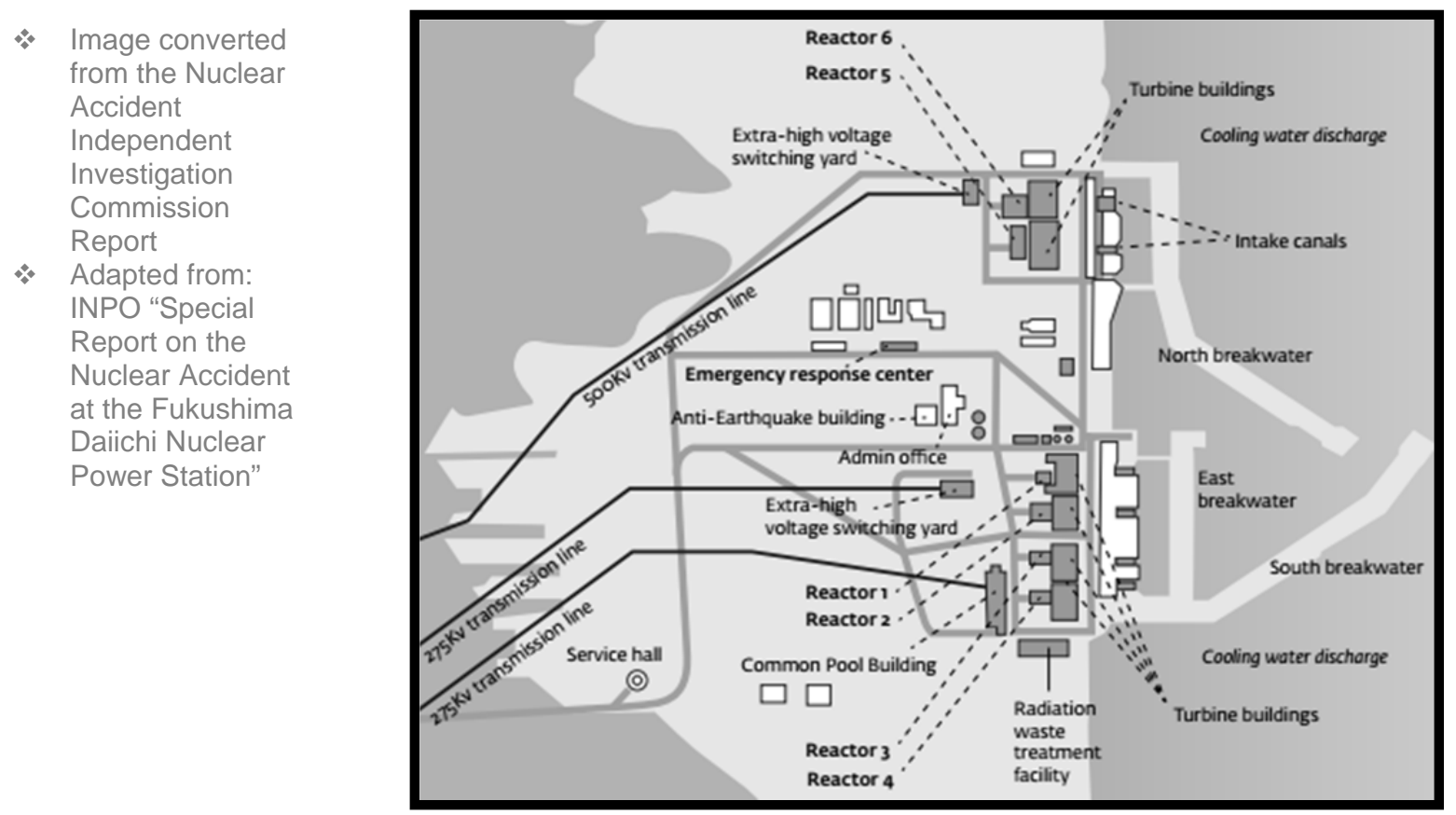

Figure 3: Layout of the Fukushima Daiichi Nuclear Power Plant

On March 11, 2011, the Tohoku earthquake and subsequent tsunami caused enormous damage to Japan. These external events triggered a severe accident at the Fukushima Daiichi Nuclear Power Plant (NPP). The loss of offsite power and inability to bring online onsite backup power caused core melting which eventually caused a Level 7 event according to the International Nuclear Event Scale. The incident occurred after the large seismic event was recorded off the shore Sendai, Japan. The seismic tremors triggered a tsunami that devastated communities along the coastline of Japan, including the Fukushima Daiichi Nuclear Facility. The Nuclear Accident Independent Investigation Commission (NAIIC) concluded:

“- the direct causes of the accident were all foreseeable prior to March 11, 2011.

But the Fukushima Daiichi Nuclear Power Plant was incapable of withstanding the earthquake and tsunami that hit on that day. The operator (TEPCO), the regulatory bodies (NISA and NSC) and the government body promoting the nuclear power industry (METI), all failed to correctly develop the most basic safety requirements - such as assessing the probability of damage, preparing for containing collateral damage from such a disaster, and developing evacuation plans for public in the case of serious radiation release."

At the Fukushima Daiichi NPP site TEPCO performed geotechnical exploration and installed seismic instrumentation, surface and downhole, prior to the seismic event. The seismic data recorded during the Tohoku earthquake was purchased from TEPCO and may be used to perform a case study of the NPP. 


\section{Fukushima Seismic Data}

Seismic data gathered at the Fukushima Daiichi NPP site may be used to develop a case study that will allow for advancing the seismic probabilistic risk assessment methods implemented at U.S. NPP's. Ideally, using the event that caused the severe accident to examine traditional SPRA methods will permit removing the conservatism in this methodology.

An INL intern gathered the soil site and dynamic soil data that would be used in traditional and advanced SPRA studies. This information is documented in Appendix A.

\section{Plan Overview}

The intent of this project plan is to establish an outline for the technical approach to be implemented by comparing a traditional SPRA with an advanced SPRA at a NPP.

The plan includes the following elements:

- Earthquake Ground Motion: Seismic hazard, ground response spectra, and associated spectrumcompatible acceleration time histories.

- Soil Properties: Median soil profile (unit weight, Poisson's ratio, strain-compatible shear modulus, and damping), dynamic soil properties, and associated variability's.

- $\quad$ Representative NPP Structure: Structure configuration and associated fixed-base model.

- Plant System: Components of the representative plant system, locations in the structure, failure modes to be considered, fault trees and event trees, and system logic model.

- Seismic Response Analysis: Median SSI model, and response analysis methods for the traditional and advanced SPRA approaches.

- Seismic Fragility Evaluation: Subset of components requiring seismic fragility evaluation, seismic fragility evaluation methodology for traditional SPRA, and approach for determination of seismic capacity distributions for advanced SPRA.

- SCDF Quantification: Methods for calculating the SCDFs by the traditional SPRA and NLSSI analysis SPRA.

- Resources: Sources of information and data that may be used in the project.

\subsection{Technical Approach \\ 5.2 Earthquake Ground Motion}

The earthquake ground motion will be based on the seismic hazard for the chosen case study NPP. Figure 4 shows an example seismic hazard curve expressed in terms of the horizontal peak ground acceleration (PGA) and associated mean annual frequency of exceedance (MAFE). The Reference Earthquake for the traditional SPRA seismic fragility evaluation will nominally be defined as the uniform hazard spectra (UHS) for the NPP. Figure 5 shows example 5\% damped horizontal and vertical Reference Earthquake UHS. The case study will use a suite of thirty sets of earthquake ground motion time histories compatible with the Reference Earthquake UHS. The horizontal time histories account for variability of the spectral acceleration in any arbitrary direction to the geomean of the two horizontal components. The vertical time histories include variability introduced when the vertical UHS are generated from the horizontal UHS by vertical-to-horizontal $(\mathrm{V} / \mathrm{H})$ ratios.

For the advanced SPRA INL will perform a number of NLSSI analyses at multiple ground motion levels, expected to range from 3 to 5 bins. Each ground motion level will be defined by a PGA (since the UHS 
shapes are assumed to be constant). PGAs for consecutive ground motion levels will represent progressive increases by factors of 1.5 times.

The UHS is typically conservative since it is an envelope of all ground motions. Therefore this case study will evaluate the change in SCDF when using ground motions that are produced from a conditional mean spectrums (CMS), which is more representative of actual earthquakes (not an envelope of all earthquakes for a given site).

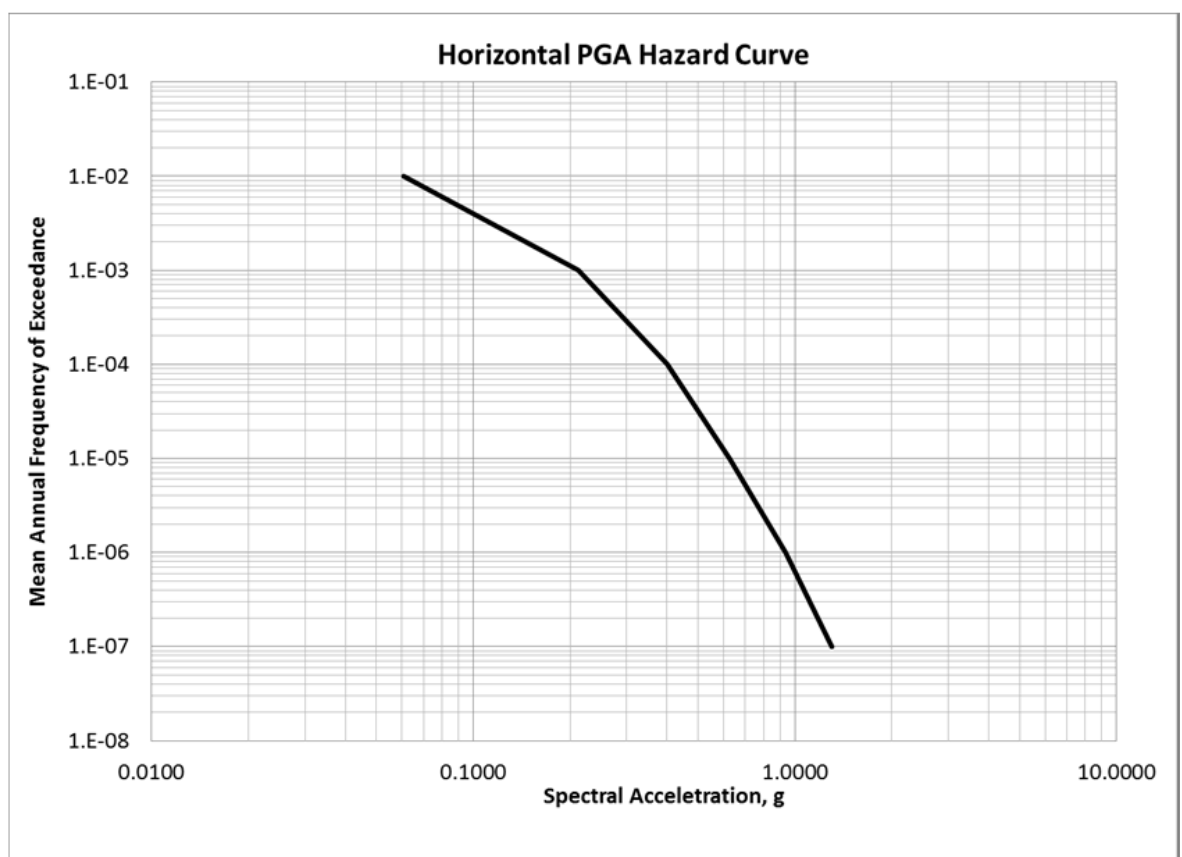

Figure 4: Seismic Hazard Curve for Horizontal PGA

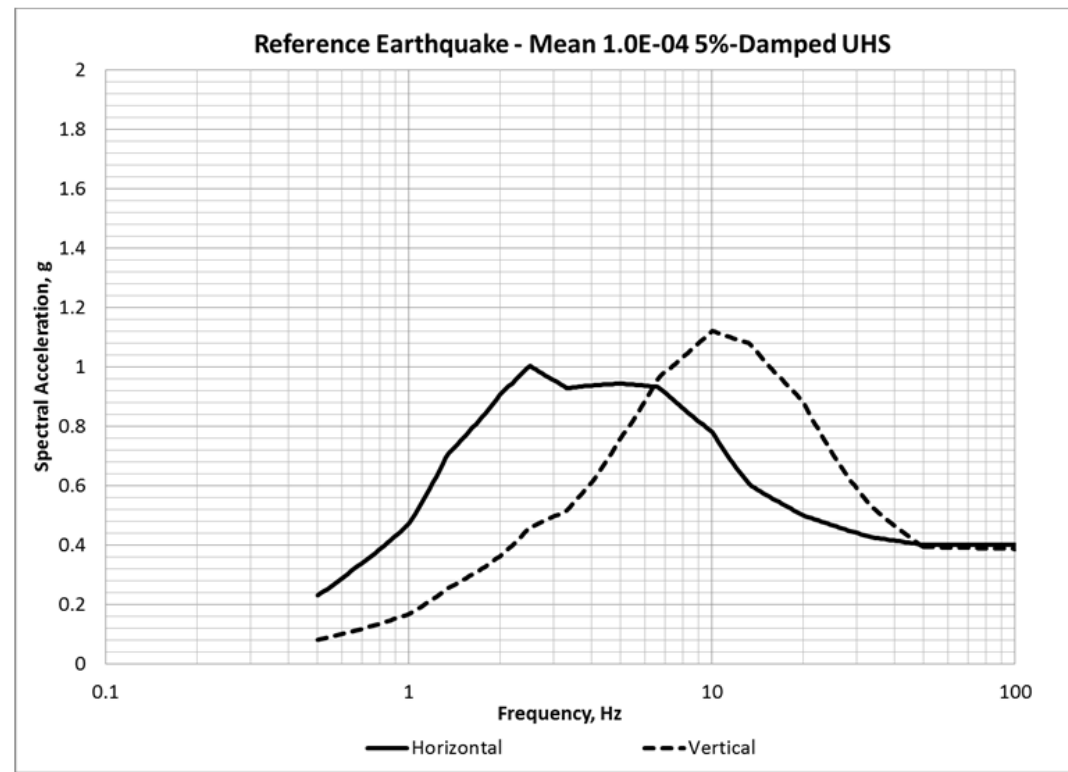

Figure 5: UHS for Mean Annual Frequency of Exceedance of 1.0E-04 


\subsection{Soil Properties}

The case study will use the soil profile that represents near field site conditions at the representative NPP. Elastic and dynamic soil properties will be needed for finite element modeling.

\subsection{Nuclear Power Plant Structure}

Data (such as drawings and component details) will have to be gathered on the NPP used in the case study.

\subsection{Plant System}

\subsubsection{Equipment Components}

Components will be selected from the applicable NPP selected for the case study. The components will be from several plant systems that impact core damage.

\subsubsection{System Logic Model}

System logic models will be developed using the components.

\subsection{Traditional Seismic Probabilistic Risk Assessment}

\subsubsection{Probabilistic Seismic Response Analysis}

A probabilistic seismic response analysis of the representative NPP structure using methods typically implemented in a traditional SPRA will be performed. Probability distributions for in-structure response spectra (ISRS) at the locations of components of the selected plant system will be generated. The analysis will consist of the following steps:

- Ground motion input will consist of thirty sets of acceleration time histories (Section 5.1).

- The fixed-base eigensolution and mass matrix will be generated for the structure model (Section 5.3).

- Foundation impedances for the median soil profile under the structure (Section 5.2) will be generated using computer program SASSI or CLASSI.

- Probability distributions of the structure frequency, structure damping, soil stiffness, and soil material damping will be represented by scale factors with median values of 1.0 and associated lognormal standard deviations. Representative lognormal standard deviations for structure frequency and damping will be used. Standard lognormal standard deviations for soil shear modulus and damping will be used.

- $\quad$ Probabilistic response analysis will likely be performed by the Latin Hypercube Sampling (LHS) approach for thirty simulations using computer program CLASSI.

- $\quad$ Five percent damped median and 84\% ISRS will be generated at the component locations. Three and a half percent damped median ISRS will also be generated.

\subsubsection{Seismic Fragility Evaluation}

Seismic fragilities will be developed for selected components using the Separation of Variables Method presented in Electric Power Research Institute (EPRI) TR-103959, supplemented by guidance in EPRI 1019200. The seismic fragility will be expressed as the probability of component failure conditional on the horizontal PGA. The seismic fragility evaluation will use existing documentation (i.e., Screening and Evaluation Work Sheets, screening calculations, and seismic fragility calculations) developed in the previous ATR DOE/EH-0545 seismic evaluation and SPRA. 


\subsection{Advanced Seismic Probabilistic Risk Assessment by Nonlinear Soil-Structure Interaction Analysis}

\subsubsection{Nonlinear Soil-Structure Interaction Analysis}

INL will perform nonlinear analysis of the representative NPP structure considering the geometric and soil nonlinearities of interest to this study. Two nonlinear effects will be studied, 1) soil nonlinearities, and 2) gapping and sliding at the foundation interface with the soil. ISRS at the locations of components of the selected plant system will be generated. This analysis will consist of the following steps:

- Ground motion input will consist of thirty sets of acceleration time histories (Section 5.1). The case study will perform sensitivity studies to determine the effect of using UHS versus CMS on SCDF.

- A median-centered nonlinear model of the structure and soil using a NLSSI method will be developed. Median soil and structure properties will follow Sections 5.2 and 5.3.

- For each of the ground motions levels, each of the thirty NLSSI model realizations will be analyzed for the associated earthquake acceleration time history set.

- For each of the thirty simulations for each of the ground motion levels, output will consist of $5 \%$ and 3.5\% damped ISRS at the component locations, and 5\% damped ISRS and acceleration time histories at the foundation centroid.

\subsubsection{Component Response Distributions}

Traditional SPRAs use parameters to define SSC fragility curves that are poorly correlated to the damage of that SSC. For instance peak ground acceleration (PGA) is typically used to define failure of an SSC when this parameter is poorly correlated to damage of SSC's. This case study will calculate the seismic fragilities using parameters that are strongly correlated to component failure and compare those with fragilities developed using current practice (fragility curves based on PGA).

\section{Collaboration}

Collaboration is important to the success of this case study. By building a strong team to guide the activities and perform the necessary tasks the outcome will be successful. This case study will require an industry partner (owner of case study NPP), EPRI, INL, and industry SPRA experts. It will also require collaboration with the Japanese. 


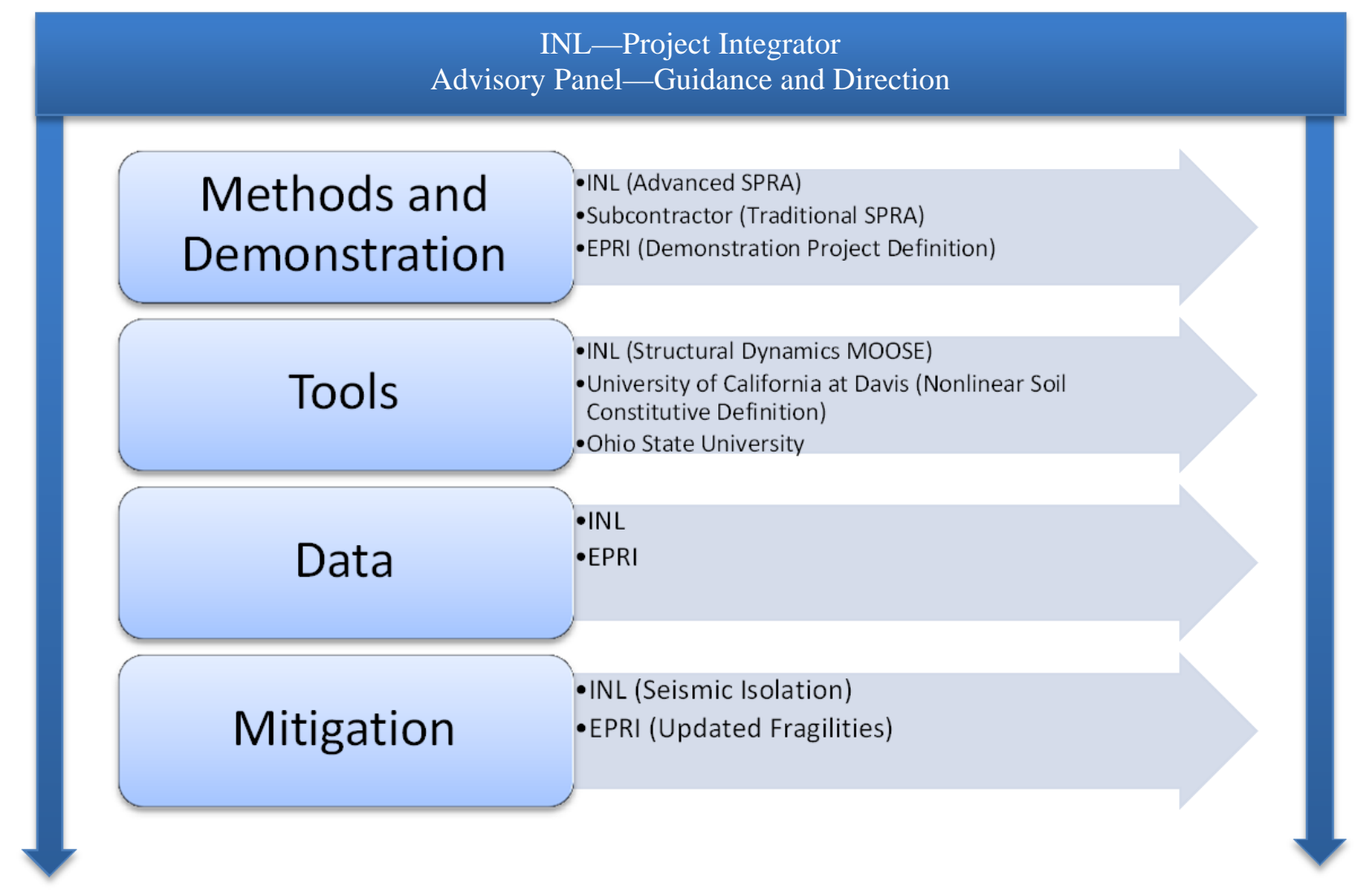

\section{References}

Coleman, Justin, "Demonstration of NonLinear Seismic Soil Structure Interaction and Applicability to New System Fragility Seismic Curves,” September 2014.

Virginia Electric and Power Company, "Virginia Electric and Power Company (Dominion) North Anna Power Station Units 1 And 2 North Anna Independent Spent Fuel Storage Installation Summary Report of August 23. 2011 Earthquake Response And Restart Readiness Determination Plan,” September 17th, 2011.

NAIIC, The National Diet of Japan The official report of, "The Fukushima Nuclear Accident Independent Investigation Commission,” 2012.

TEPCO 1, "Acceleration Time-History Waveforms of the 2011 Pacific coast of Tohoku Earthquake observed at Fukushima Daiichi and Daini NPP," CD-ROM.

TEPCO 2, “Acceleration Time-History Waveforms of Niigata-Chuestsu-Oki Earthquake Collected at Kashiwazaki-Kariwa Nuclear Power Station,” CD-ROM. 
Appendix A: Fukushima Daichii site specific report 


\section{Input Parameters for Non-Linear Seismic Analysis of a Nuclear Power Plant:}

Fukushima Daiichi Seismic Event of 2011

Callan E. McGriff ${ }^{\text {a, b }}$

${ }^{a}$ Idaho National Laboratory, Idaho Falls, Idaho, United States

${ }^{\mathrm{b}}$ University of Idaho, Moscow, Idaho, United States

Date Issued: August 2014 


\section{INTRODUCTION}

In the United States (U.S.), economic uncertainties for nuclear power plants have generated a dormant status for new assembly. Recent reports conclude that approximately $80 \%$ of the KWH cost is due to capital investment in nuclear plants (source MIT 2009). Throughout 1953 to 2008, 253 nuclear energy reactors were ordered for operation in the United States. Of the 253 reactors originally ordered, $48 \%$ were cancelled.

A potential cost driver for new and existing plants is construction in areas with high seismicity. In certain instances, overly conservative nuclear power plant seismic design and risk assessment may escalate capital cost. The seismic hazard may be perceived or tangible; however, defense in depth for structural stability in the event of seismic activity may cause unnecessary investment.

Nuclear Regulatory Commission (NRC)'s primary mission is ensuring the safe use of radioactive materials for civilian purposes and protecting people and the environment. This emphasis is reinforced by focusing on radiation protection, reactor safety, and regulation of nuclear materials. In order to construct a new nuclear plant domestically, proof of concept must be certified by the NRC, providing evidence that public safety is maintained by providing acceptably low levels of risk.

On March 11, 2011, the Tohoku earthquake and subsequent tsunami caused enormous damage to Japan. These external events triggered a severe accident at the Fukushima Daiichi Nuclear Power Plant (NPP). The loss of offsite power and inability to bring online onsite backup power caused core melting which eventually caused a Level 7 event according to the International Nuclear Event Scale. The incident occurred after the large seismic event was recorded off the shore Sendai, Japan. The seismic tremors triggered a tsunami that devastated communities along the coastline of Japan, including the Fukushima Daiichi Nuclear Facility. It is mentioned that multiple independent studies have been executed after the events of the Fukushima nuclear accident. The Nuclear Accident Independent Investigation Commission (NAIIC) concludes:

“- the direct causes of the accident were all foreseeable prior to March 11, 2011. But the Fukushima Daiichi Nuclear Power Plant was incapable of withstanding the earthquake and tsunami that hit on that day. The operator (TEPCO), the regulatory bodies (NISA and NSC) and the government body promoting the nuclear power industry (METI), all failed to correctly develop the most basic safety requirements - such as assessing the probability of damage, preparing for containing collateral damage from such a disaster, and developing evacuation plans for public in the case of serious radiation release.

The Commission has discovered that no part of the required reinforcements has been implemented on Units 1 through 3 by the time of the accident. This was the result of tacit consent by NISA for a signification delay by the operators in completing the reinforcement."

At the Fukushima Daiichi NPP site TEPCO performed geotechnical exploration and installed seismic instrumentation, surface and downhole, prior to the seismic event. The seismic data recorded during the Tohoku earthquake was purchased from TEPCO and will be used to perform studies of the NPP using advanced seismic probabilistic risk assessment (SPRA). Details are documented for the main shock and six aftershocks. 


\section{$\underline{\text { PURPOSE }}$}

Seismic data gathered at the Fukushima Daiichi NPP site will be used to develop a case study that will allow for advancing the seismic probabilistic risk assessment methods implemented at U.S. NPP's. Ideally, using the event that caused the severe accident to examine traditional SPRA methods will permit removing the conservatism in this methodology. The proposal is to replace the traditional SPRA method with an advanced SPRA method to remove conservatism and modeling the best estimate for risk.

The intention of this paper is to discuss the methods of filtering through a surplus of data to frame the structural details, soil profiles, and seismic data from Fukushima Daiichi records. This inquiry of Fukushima Daiichi documents shaped the input parameters for non-linear seismic analysis that will be utilized to further advance external hazard risk mitigation capabilities. Input parameters include the elastic and dynamic soil properties associated with the Fukushima Daiichi NPP.

\section{BACKGROUND}

Fukushima Daiichi NPP is owned and operated by the Tokyo Electric Power Company (TEPCO). The facility is located on the Japanese coastline, surrounded by the cities of Fukushima, Iwaki, Minamisoma, Nihonmatsu, and Sendai. Figures 1 and 2 depict the location of Fukushima Daiichi relative to the country boarders.

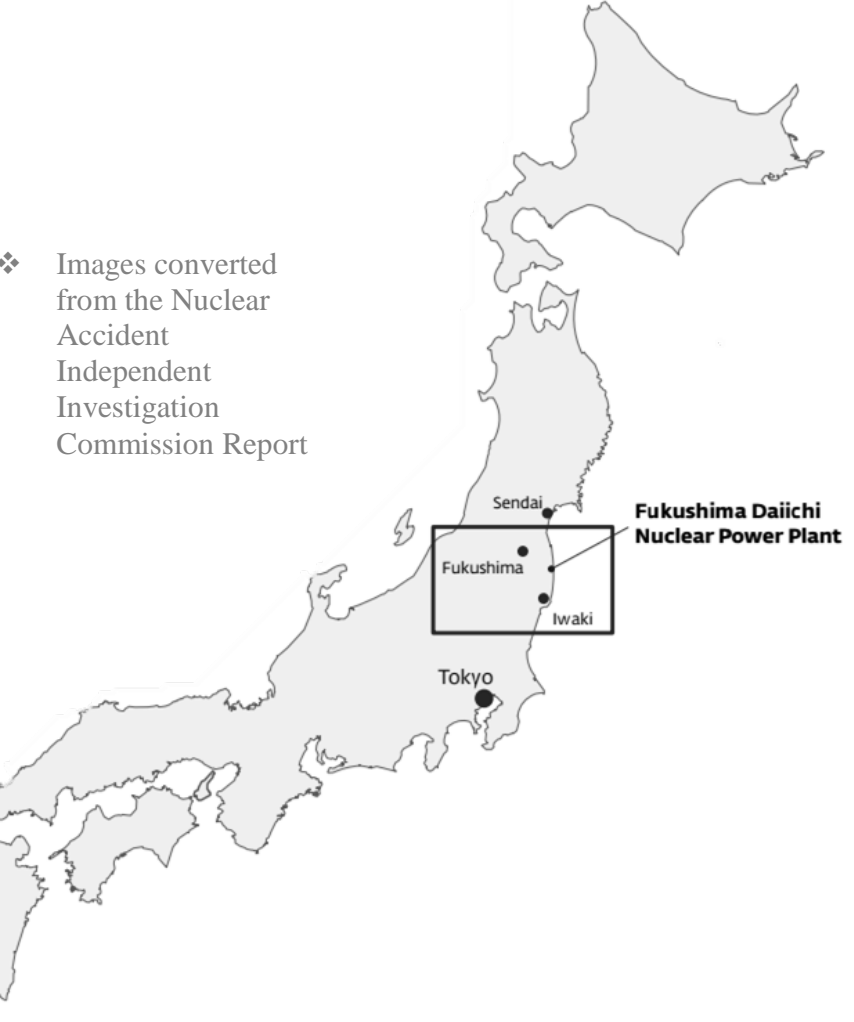

Figure 1: The country of Japan outlining cities relevant to the Fukushima Daiichi NPP

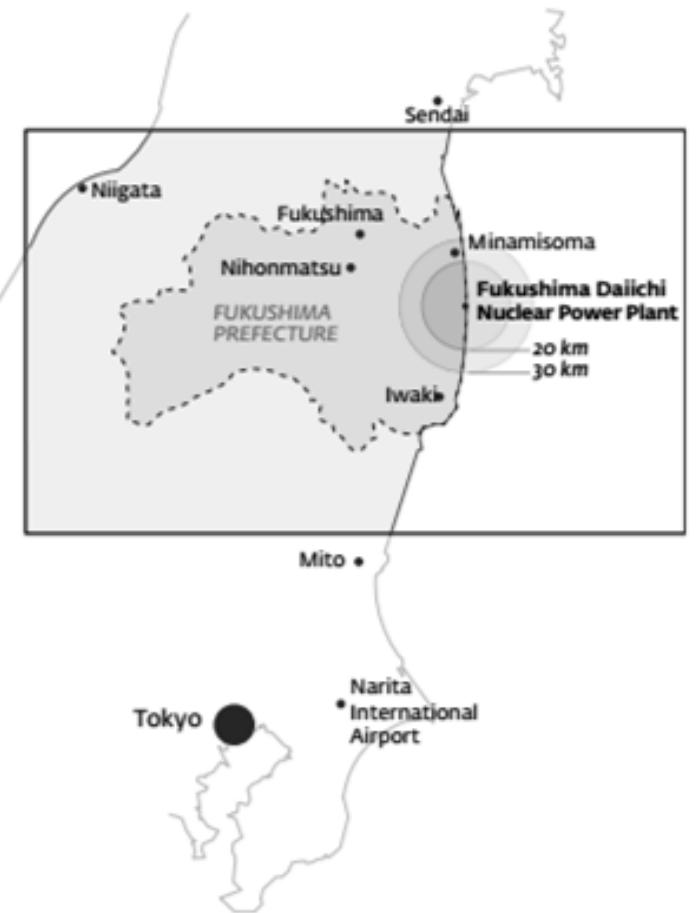

Figure 2: Magnifies the location of the Fukushima Daiichi NPP and surrounding areas 
The nuclear facility consists of Reactor Units 1 through 6 . Details of the effects of the seismic and tsunami events on the reactors can be referenced in the NAIIC report. Figure 3, provided by the NAIIC report, outlines in detail the layout of the Fukushima Daiichi NPP. The image was used to reference the location of the observation sites for the geotechnical analysis of the region.

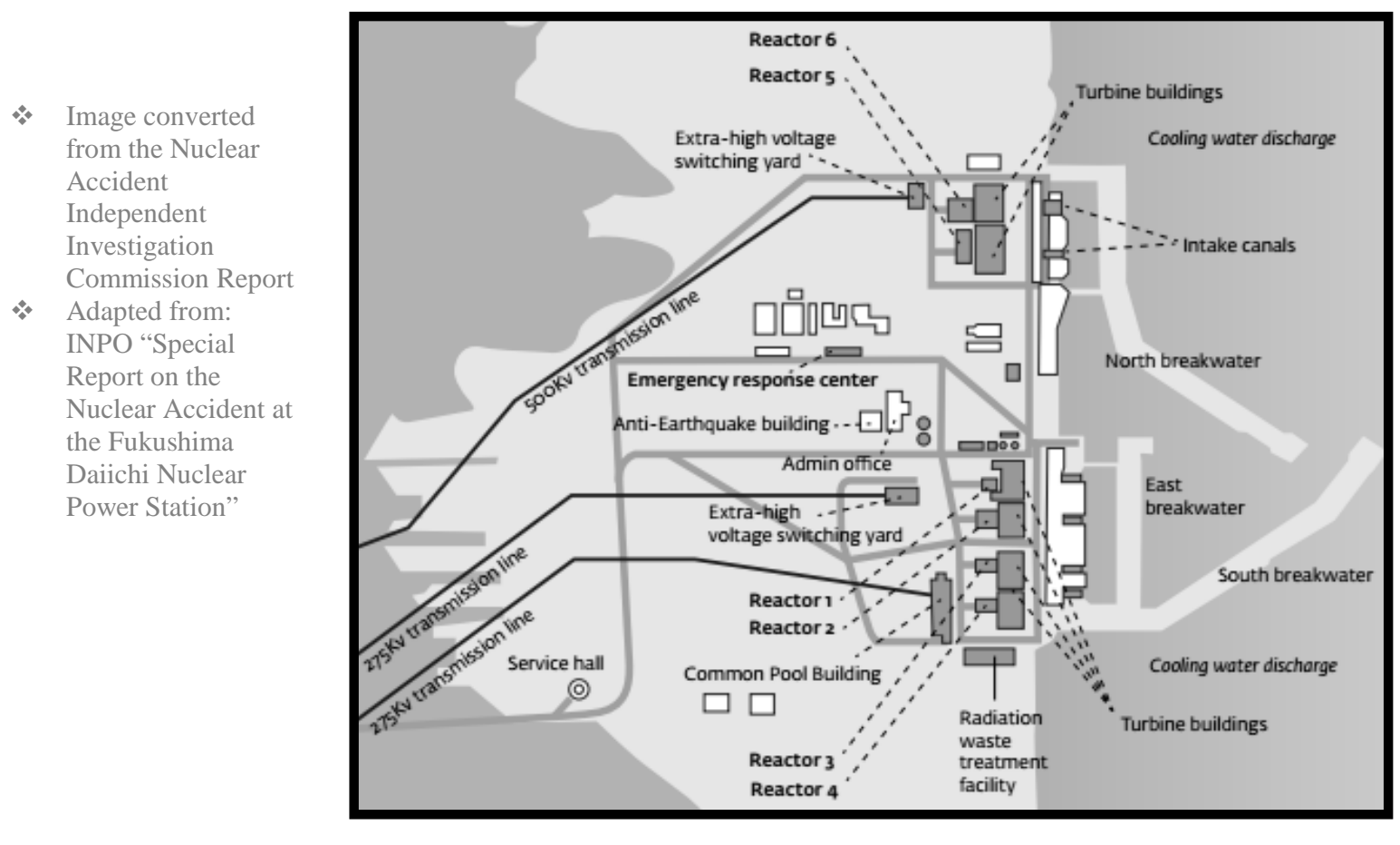

Figure 3: Layout of the Fukushima Daiichi Nuclear Power Plant

\section{$\underline{\text { SITE DETAILS }}$}

Four boreholes were drilled according to the TEPCO records. A free field borehole array was documented at the North and South points of the nuclear facility. Data was also monitored at boreholes near Unit 6, and Unit 5. Figure 4 displays the locations of the observation points on site where schematic information was retrieved.

The soil layers present at the site are depicted from the borehole information provided by TEPCO. There is uncertainty in the exact depth of a substratum level below the surface. The layer thickness, approximated depths, and observation points are projected in Figure 5. The soil description consists of alternating Sandy Loams, Mudstones, Gravel, Sandstones, and Fine Sands. More detail on the stratigraphy is noted in Figure 5 for defined soil layering. 


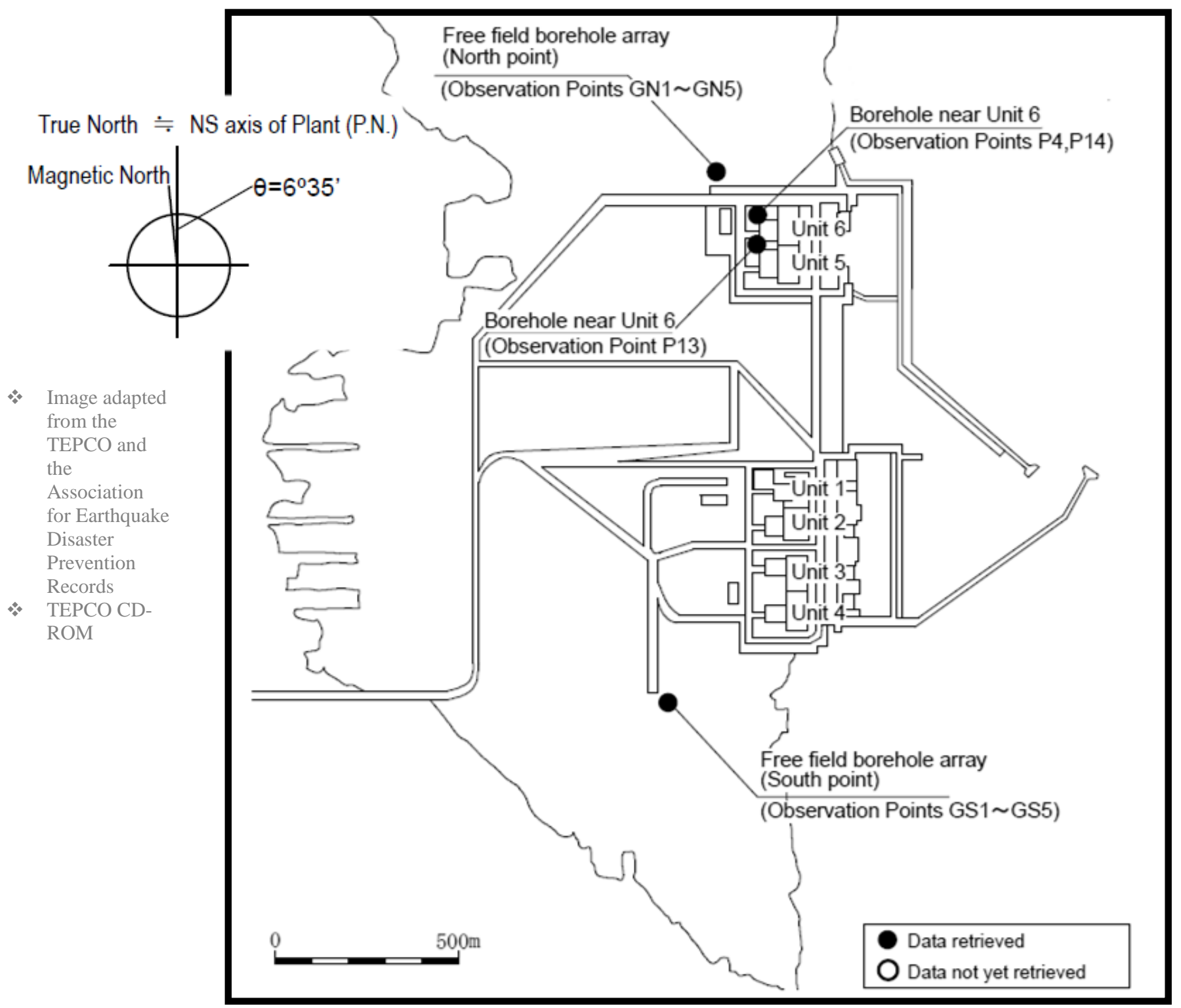

Figure 4: Fukushima Daiichi Nuclear Power Plant Schematic Location of Boreholes on Site 


\section{Soil Strata for Fukushima Daiichi Boreholes}

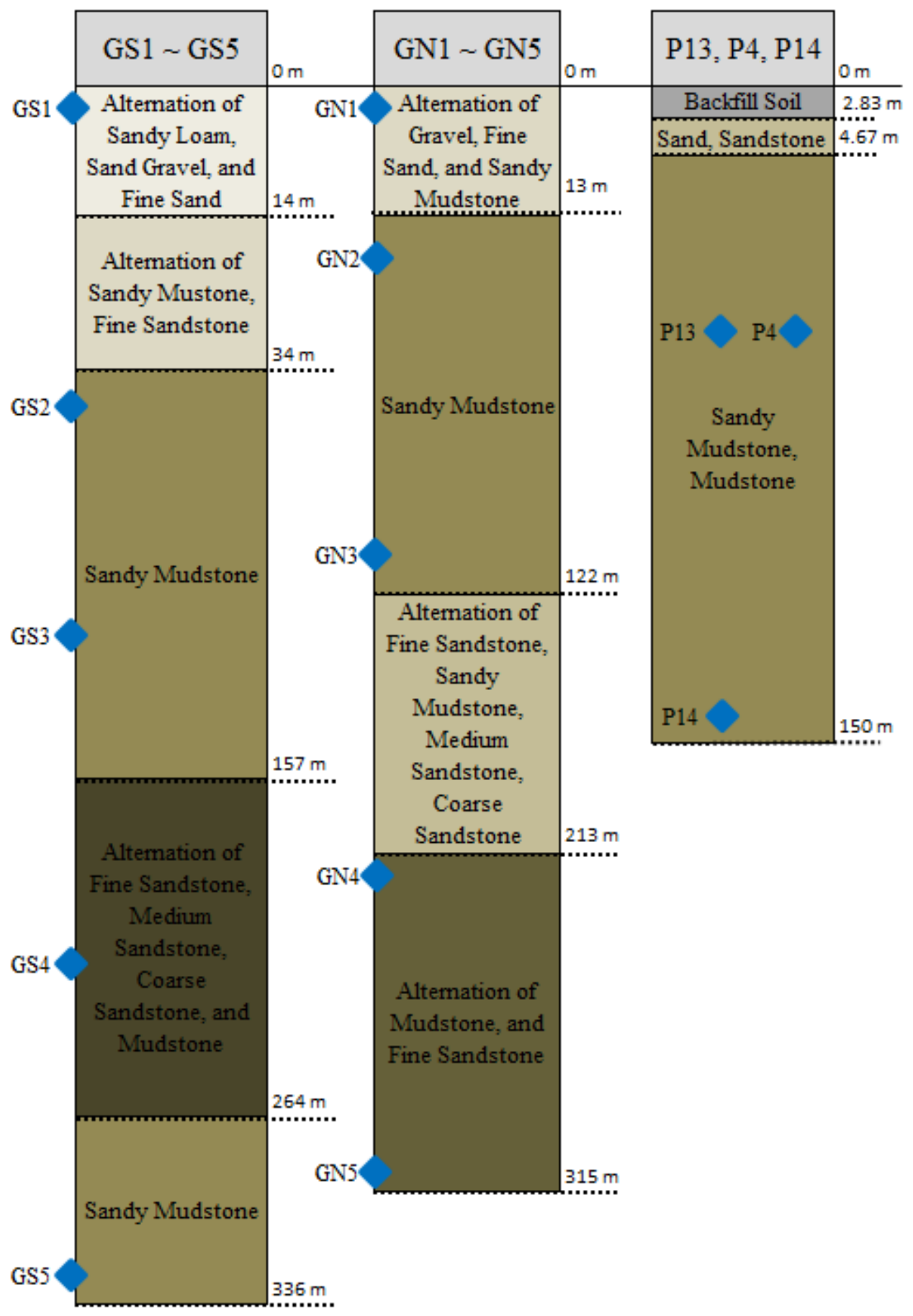

Figure 5: Interpreted Soil Layering for Boreholes Designated in Figure 4 
The soil in the Japan area is dominantly classified as variations of mudstone. The Geological Society specifies Mudstone as "-made of tiny clay particles. These tiny particles are deposited in quiet low energy environments like tidal flats and deep sea."

\section{MATERIAL PROPERTIES}

\section{Fukushima Daiichi Seismic Data}

Seismic observation data and ground motion simulation files were supplied by TEPCO. The information provided contains acceleration time history plots. PDF files include locations and characteristics of seismometers and soil conditions at the nuclear power plant. Borehole locations are identified in Figure 4, above.

The geological stratum and location of seismometers at approximate depths and altitude were denoted in the TEPCO Fukushima Daiichi File \#3 for the boreholes specified. Similarly, Elastic Wave Velocity diagrams were present for each borehole array. Figure 6 is an independent chart graph generated from the supplied TEPCO data. Original figures can be referenced from the TEPCO CD-ROM No. 1032 distributed by The Association for Earthquake Disaster Prevention.

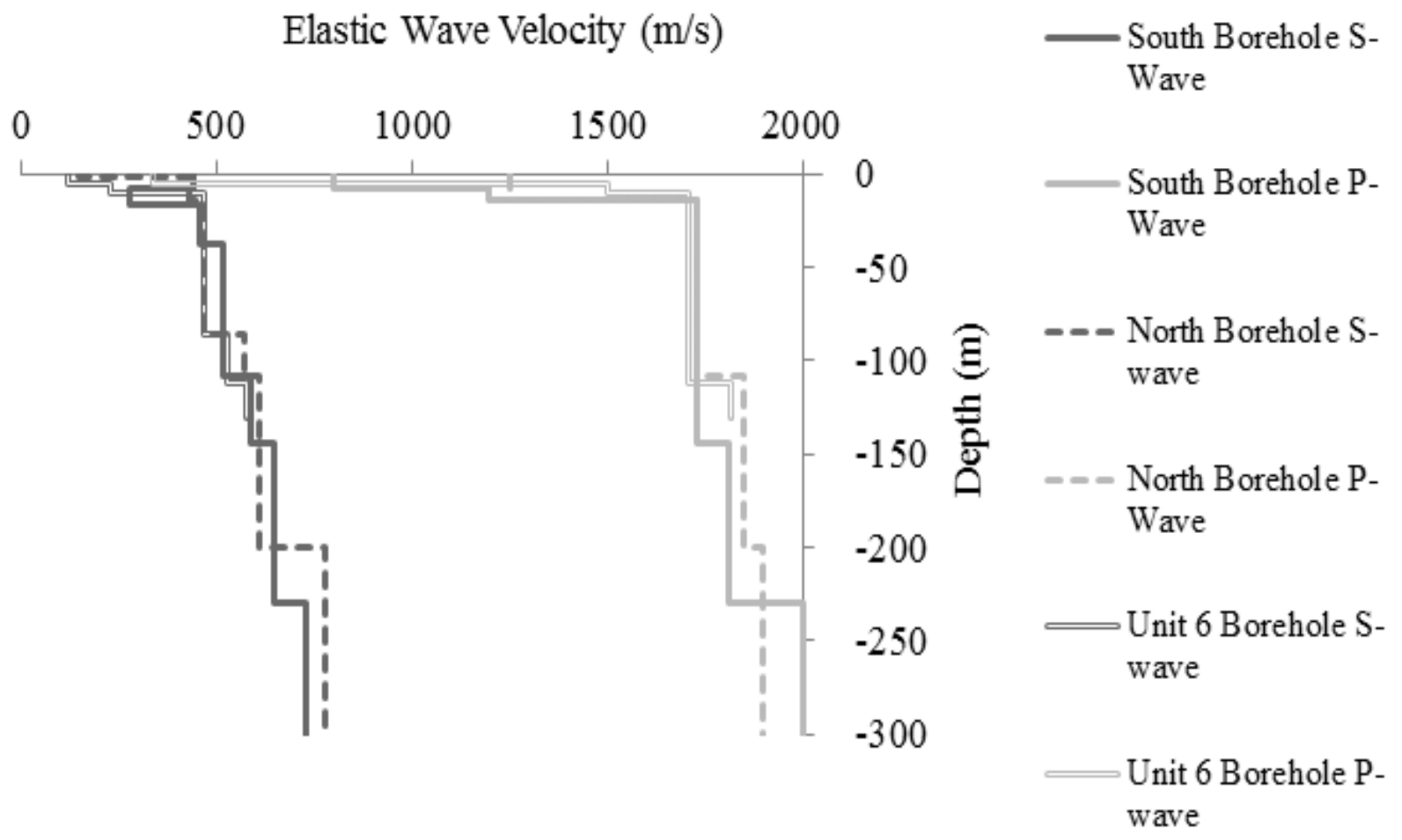

Figure 6: Elastic Wave Velocities for designated boreholes. Information utilized in TEPCO data files 


\section{Elastic Properties}

It is mentioned that a surplus of Fukushima Daiichi soil data was provided by TEPCO. This data was filtered through to frame the structural details, and soil profiles seen in Figure 4, above. The elastic properties of the soil stratum were calculated from the recorded elastic wave velocities.

Table 1 summarizes the provided data from the seismometers. The maximum recorded acceleration in north-south, east-west, and up-down directions, shear wave, and compression wave velocities for each observation point are listed respectively in gals $\left(\mathrm{cm} / \mathrm{s}^{2}\right)$ and $\mathrm{m} / \mathrm{s}$.

Table 1: Maximum Accelerations recorded in three directions for borehole locations

\begin{tabular}{|c|c|c|c|c|c|c|c|c|}
\hline \multirow{2}{*}{ Location } & \multirow{2}{*}{ Depth (m) } & \multirow{2}{*}{ Altitude } & \multirow{2}{*}{$\begin{array}{l}\text { Obs. } \\
\text { Pt. }\end{array}$} & \multicolumn{3}{|c|}{ Max Acceleration (Gal) } & \multirow{2}{*}{$\begin{array}{c}\text { Shear Velocity } \\
\beta(\mathrm{m} / \mathrm{s})\end{array}$} & \multirow{2}{*}{$\begin{array}{l}\text { Compressional } \\
\text { Wave } \alpha(\mathrm{m} / \mathrm{s})\end{array}$} \\
\hline & & & & NS & EW & UD & & \\
\hline \multirow{5}{*}{$\begin{array}{l}\text { Free field } \\
\text { borehole array } \\
\text { (South) }\end{array}$} & -2.0 & O.P $+32.9 \mathrm{~m}$ & GS1 & 463 & 600 & 326 & 440 & 800 \\
\hline & -39.9 & O.P $-5.0 \mathrm{~m}$ & GS2 & 250 & 345 & 142 & 520 & 1730 \\
\hline & -134.9 & O.P $-100 \mathrm{~m}$ & GS3 & 249 & 321 & 153 & 590 & 1730 \\
\hline & -234.9 & O.P $-200 \mathrm{~m}$ & GS4 & 242 & 355 & 163 & 730 & 2000 \\
\hline & -334.9 & O.P $-300 \mathrm{~m}$ & GS5 & 242 & 360 & 154 & 730 & 2000 \\
\hline \multirow{5}{*}{$\begin{array}{c}\text { Free field } \\
\text { borehole array } \\
\text { (North point) }\end{array}$} & -2.0 & O.P $+12.2 \mathrm{~m}$ & GN1 & 570 & 699 & 239 & 150 & 1250 \\
\hline & -19.2 & O.P $-5.0 \mathrm{~m}$ & GN2 & 293 & 456 & 166 & 470 & 1730 \\
\hline & -114.2 & O.P $-100 \mathrm{~m}$ & GN3 & 313 & 258 & 143 & 610 & 1850 \\
\hline & -214.2 & O.P $-200 \mathrm{~m}$ & GN4 & 250 & 220 & 116 & 780 & 1900 \\
\hline & -314.4 & O.P $-300 \mathrm{~m}$ & GN5 & 231 & 248 & 106 & 780 & 1900 \\
\hline \multirow{3}{*}{$\begin{array}{c}\text { Borehole near } \\
\text { Unit } 6\end{array}$} & -31.5 & O.P $-18.0 \mathrm{~m}$ & P13 & 252 & 405 & 194 & 470 & 1710 \\
\hline & -31.5 & O.P $-18.0 \mathrm{~m}$ & $\mathrm{P} 4$ & 209 & 387 & 189 & 470 & 1710 \\
\hline & -143.5 & O.P $-130 \mathrm{~m}$ & P14 & 313 & 302 & 113 & 580 & 1820 \\
\hline
\end{tabular}

The elastic properties were determined for the subsurface by referencing the Central Federal Lands Highway geophysical methodology. Equations 1 through 4, below, were utilized to determine the elastic constants from the shear wave and compressional wave velocities seen in Figure 6, above, and Table 1, above.

Equation $1 \quad v=\frac{V P^{2}-2 V S^{2}}{2\left(V P^{2}-V S^{2}\right)}$

Equation $2 \quad E=\rho V S^{2}\left[\frac{3 V P^{2}-4 V S^{2}}{V P^{2}-V S^{2}}\right]$

Equation $3 \quad G=\frac{E}{2(1+v)}$

Where E is the Young's Elastic Modulus (unit in Pascals), G is the Shear Modulus (unit in Pascals), $\rho$ is the density of the soil (unit in $\mathrm{kg} / \mathrm{m} 3$ ), $v$ and is Poisson's Ratio (unitless) 
It is noted that the density for the soil was not provided in the TEPCO files. Density is a parameter necessary for evaluating seismic data and formulating elastic properties from shear and compressional velocities. To estimate adequate densities for the Fukushima Daiichi area, Gardner's Empirical Relationship was used to determine the dynamic density in the soil stratum.

\section{Equation $4 \quad \rho=a V P^{x}$}

Where a \& $\mathrm{x}$ are constants equaling 0.31 and 0.25 respectively, and VP is the compressional wave velocity (unit in $\mathrm{m} / \mathrm{s}$ )

Assumptions considered for Gardner’s Empirical Relationship Equation 4 include:

- the soil stratum is compiled of a variation of sandstone/mudstone layers

- the bulk density is given in $\mathrm{g} / \mathrm{cm}^{3}$

- if velocity is in $\mathrm{m} / \mathrm{s}, \mathrm{a}=0.31$

- $\mathrm{x}=0.25$

- $\quad$ RMS error $=0.1147$

Table 2 displays the calculated results for the elastic properties at the observation points in the borehole locations identified in Figure 4, above.

Table 2: Elastic Properties for observation points

\begin{tabular}{c|crccc}
\hline Location & $\begin{array}{c}\text { Obs. } \\
\text { Pt. }\end{array}$ & \multicolumn{1}{c}{$\begin{array}{c}\text { Density } \\
\left(\mathrm{kg} / \mathrm{m}^{3}\right)\end{array}$} & $\begin{array}{c}\text { Poisson's Ratio } \\
v\end{array}$ & $\begin{array}{c}\text { Young's Mod. E } \\
(\mathrm{Pa})\end{array}$ & $\begin{array}{c}\text { Shear Modulus } \\
\mathrm{G}(\mathrm{MPa})\end{array}$ \\
\hline \multirow{3}{*}{ Free field } & GS1 & 1648.671728 & 0.28 & 819121570 & 319.18 \\
borehole array & GS2 & 1999.27815 & 0.45 & 1568121307 & 540.60 \\
(South) & GS3 & 1999.27815 & 0.43 & 1996247658 & 695.95 \\
& GS4 & 2073.094945 & 0.42 & 3144454317 & 1104.75 \\
& GS5 & 2073.094945 & 0.42 & 3144454317 & 1104.75 \\
\hline & GN1 & 1843.271028 & 0.49 & 123814849 & 41.47 \\
Free field & GN2 & 1999.27815 & 0.46 & 1289727403 & 441.64 \\
borehole array & GN3 & 2033.080739 & 0.44 & 2177245992 & 756.51 \\
North point) & GN4 & 2046.680699 & 0.40 & 3483209552 & 1245.20 \\
& GN5 & 2046.680699 & 0.40 & 3483209552 & 1245.20 \\
\hline Borehole near & P13 & 1993.474669 & 0.46 & 1285090459 & 440.36 \\
Unit 6 & P4 & 1993.474669 & 0.46 & 1285090459 & 440.36 \\
& P14 & 2024.787919 & 0.44 & 1966421665 & 681.14
\end{tabular}




\section{Dynamic Properties}

Dynamic soil properties are interpreted from laboratory testing performed on soil samples taken at various borehole locations. It is noted that laboratory information was not present in the TEPCO CD-ROM files.

A seismic event was recorded in Makinohara, Japan, approximately 464 kilometers south of the Fukushima Daiichi Nuclear Power Plant. The laboratory testing recorded at Makinohara concluded and classified the site as primarily Mudstone, the dominant soil present at the site focus for this project.

The dynamic soil properties for this project were derived from the publicly disclosed report titled Reduction of static and dynamic shear strength due to the weathering of mudstones (15 WCEE).

Figures 7 and 8 depict the dynamic soil data interpreted from the 15 WCEE Report. The graphs are viewed as linear log plots. Cyclic torsional shear and triaxial tests were implemented to adequately determine the dynamic behaviors of the soil site.

Six series of testing were completed to demonstrate the effects of slaking on the damping ratio and the shear modulus. The reference points represented in Figures 7 and 8 depict various slaking applied. For the purpose of this project, the data from the Japanese report is utilized to represent the input parameters for representative dynamic properties with no slaking applied.

Noted assumptions of the Makinohara data depicted in Figures 7 and 8 include:

Laboratory Considerations

- 11 cycles of cyclic loading were applied

- Confining pressure is recorded at $50 \mathrm{kPa}$

- Small amplitude

- Amplitude of cyclic loading was increased step by step until failure

Soil Characteristics

- Primarily Mudstone

- Undrained soil conditions

- Earthquake magnitude = 6.5 August 11, 2009 


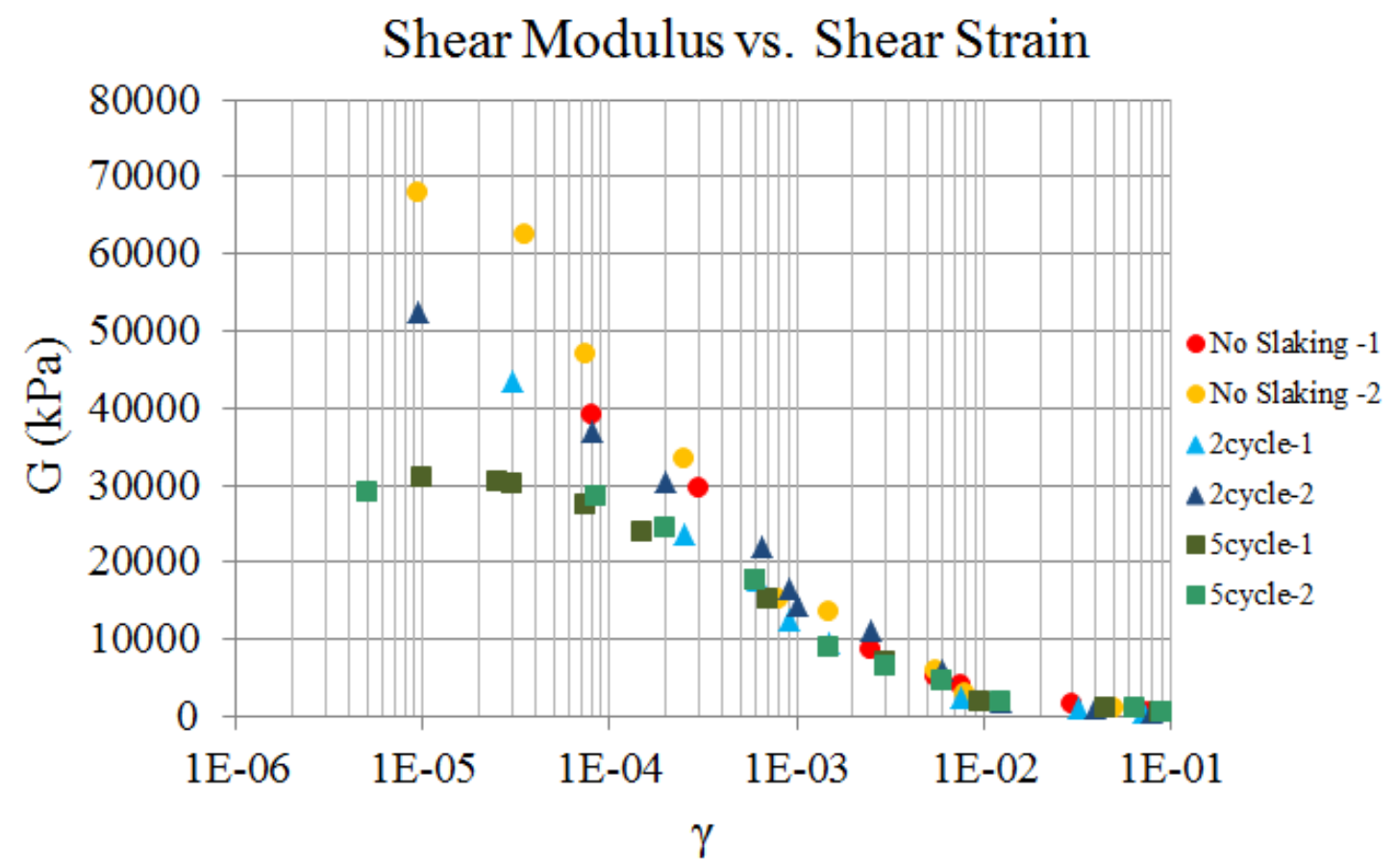

Figure 7: Shear Modulus versus the Shear Strain relationship. Where G is the shear modulus (unit in $\mathrm{kPa}$ ), and $\gamma$ is the shear strain (in/in). Please reference assumptions, below.

\section{Damping Ratio vs. Shear Strain}

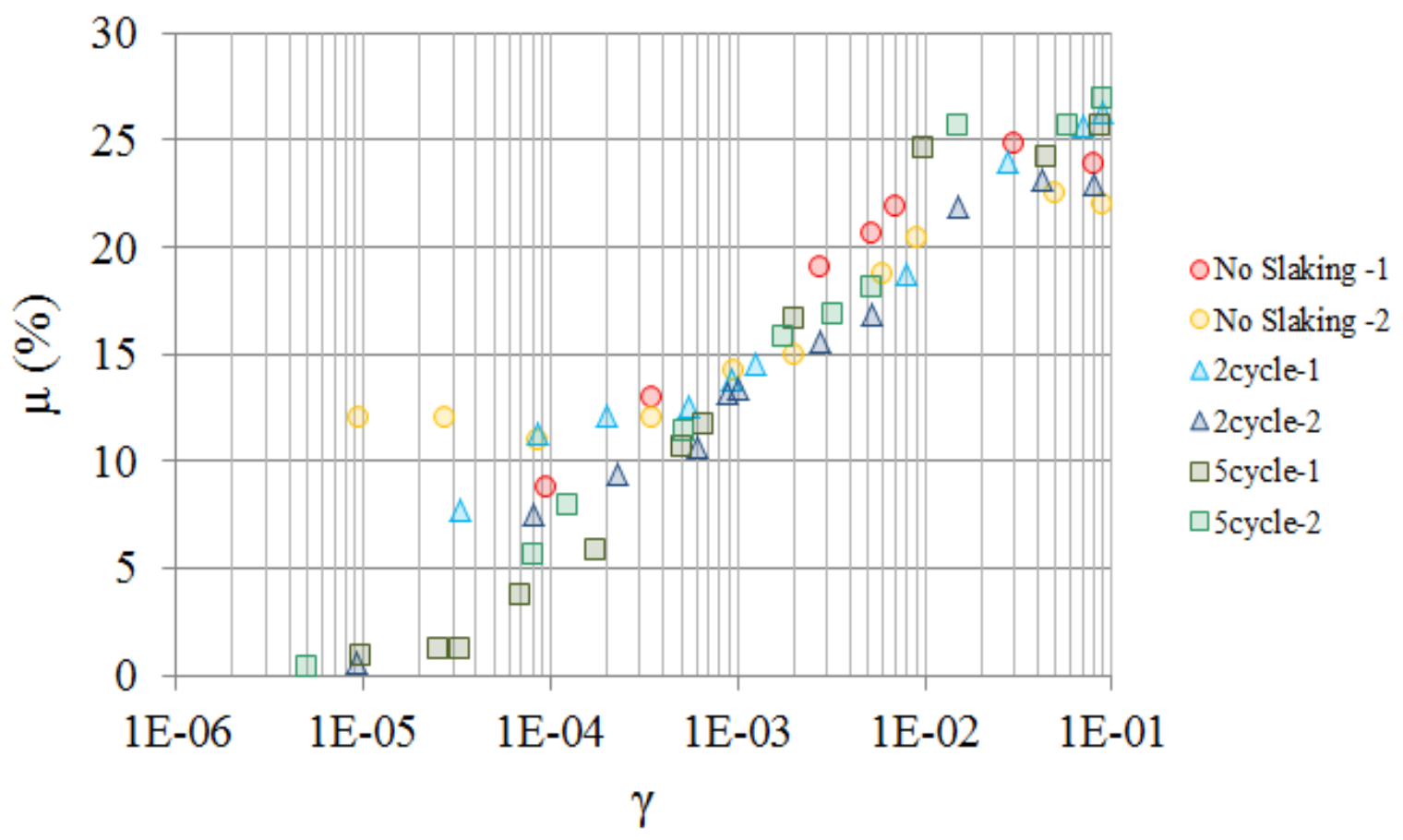

Figure 8: Damping Ratio versus the Shear Strain relationship. Where $\mu$ is the damping ratio (unit in \%) and $\gamma$ is the shear strain (in. /in.). Please reference assumptions, below. 


\section{FUTURE APPLICATION}

Numerical Finite Element Analysis on soil motion activated by seismic events can be used to evaluate the response of NPP's. Increased accuracy in numerical models may help contain construction cost at NPPs removing overly conservative results. To address the capital cost of nuclear power plants, the conservatism must be mitigated in plant design. In order to further advance external hazard risk mitigation capabilities, alternative design options need to be licensable, and provide sufficient proof of concept.

The nuclear accident at Fukushima Daiichi was determined to be a level 7 incident causing harm to the public. This event has been intensely evaluated, and the Nuclear Accident Independent Investigation Commission (NAIIC) organized by TEPCO concludes that the seismic event was not the primary factor to a nuclear design failure. However, the report does note that "TEPCO was too quick to cite the tsunami as the cause of the nuclear accident and deny that the earthquake caused any damage. We believe there is a possibility that the earthquake damaged equipment necessary for ensuring safety, and that there is also a possibility that a small-scale LOCA occurred in Unit 1. We hope these points will be examined further by a third party."

The Fukushima Daiichi elastic and dynamic properties will be used as input parameters for a numerical finite element analysis of seismic wave propagation. A non-linear seismic analysis of a nuclear facility allows for fundamental explorative options for removing conservatism when evaluating risk at NPP's. 


\section{$\underline{\text { REFERENCES }}$}

15 WCEE LISBOA 2012, Reduction of static and dynamic shear strength due to the weathering of mudstones, S. Yasuda, S. Yokota \& H. Nakamura, K. Inou, 2012, August 2014, PDF

Dynamic of Structures, Chopra, Theory and Application to Earthquake Engineering, Hardcopy Property of DOE, Pearson Education, August 2014

The Geological Society, The Rock Cycle, August 2014 <http://www.geolsoc.org.uk/ks3/gsl/education/resources/rockcycle/page3523.html>

International Energy Agency (iea), World Energy Outlook 2013, Hardcopy Property of DOE, August 2014

MIT, Massachusetts Institute of Technology, The Future of Nuclear Power, An Interdisciplinary MIT Study, 2010, August 2014

$<$ http://web.mit.edu/nuclearpower/>

Nuclear Accident Independent Investigation Commission (NAIIC), The National Diet of Japan, The official report of the Fukushima Nuclear Accident Independent Investication Commission, pdf, Executive Summary, 2012, August 2014, Hardcopy

TEPCO, Toyko Electric Power Company, 2011 CD-ROM, Japan Association for Earthquake Engineering No. 1006

The Biggest Earthquake Ever Recorded in Japan, (2011 Sendai Earthquake), March 2011, August 2014

< http://www.tofugu.com/2011/03/11/the-biggest-earthquake-ever-recorded-japan/>

U.S. NRC, Operating Nuclear Power Reactors, March 19, 2014, August 2014

$<$ http://www.nrc.gov/info-finder/reactor/> 